\title{
Originals
}

\section{Transcapillary escape rate and relative metabolic clearance of glycated and non-glycated albumin in Type 1 (insulin-dependent) diabetes mellitus}

\author{
L. Bent-Hansen, B. Feldt-Rasmussen, A. Kverneland and T. Deckert
}

Steno Memorial Hospital, Gentofte, Denmark

Summary. The transcapillary escape rate and relative plasma disappearance of glycated and non-glycated albumin were measured in 25 male Type 1 (insulin-dependent) diabetic patients using a double tracer technique. The patients were divided into three groups on the basis of their urinary albumin excretion: group 1 , normal albumin excretion $(<30 \mathrm{mg} / 24 \mathrm{~h})$ $(n=8)$; group 2, microalbuminuria ( $30-300 \mathrm{mg} / 24 \mathrm{~h})(n=9)$; and group 3, clinical nephropathy ( $>300 \mathrm{mg} / 24 \mathrm{~h})(n=8)$. Six male age-matched non-diabetic persons served as control subjects. The transcapillary escape rate of glycated albumin was similar in group 1 and control subjects $(4.7 \pm 2.1$ versus $5.1 \pm 1.7 \%)$, but significantly increased in group $2(7.0 \pm 1.7 \%$, $p<0.05)$ and in group $3(7.9 \pm 3.1 \%, p<0.05)$. The transcapillary escape rate of glycated albumin was slightly lower than that of non-glycated albumin in all groups, but significant only in normal control subjects. No difference in the catabolic rate of glycated and non-glycated albumin was found. We conclude that the in vivo effects of glycation on the clearance and transcapillary passage of albumin are small and not likely to play any significant role in the development of late diabetic microvascular complications.

Key words: Insulin-dependent diabetes, albumin leakage, glycation, microalbuminuria, diabetic nephropathy.
Increased microvascular leakage of plasma proteins seems to be closely associated with the development of severe diabetic complications [1-3]. Recently, an increased transcapillary escape rate (TER) of albumin and hypoalbuminaemia were also demonstrated in patients with microalbuminuria [4]. This indicates the presence of an advanced general microvascular dysfunction concomitant to the early rise in urinary albumin excretion, also involving albumin metabolism. The morphological or biochemical alterations related to increased TER of albumin are unknown, but haemodynamic alterations $[5,6]$ and/or alterations in the properties of the capillary wall $[7,8]$ are a possibility. Another possibility would be a differential handling by endothelial membranes of glycated and non-glycated albumin. Thus, unmodified rat albumin was shown in vitro to be excluded from ingestion by endothelial micropinocytotic vesicles, whereas glycated albumin in concentrations found in normal subjects was avidly taken up by the endothelial cells of the rat [9]. It has also been shown that non-enzymatic glycation of endothelial membrane components results in stimulated ingestion of glycated albumin in vitro [10]. However, in vivo studies in diabetic patients have produced conflicting results $[11,12]$. In the present study we investigated the simultaneous transcapillary escape rates and the relative metabolic clearance of glycated and non-glycated albumin in diabetic patients and normal control subjects.

The aim of the study was to evaluate the in vivo effects of glycation of albumin on these parameters and thereby determine a possible role in the development of diabetic microvascular complications.

\section{Subjects and methods}

Twenty-five Type 1 male diabetic patients were studied. They were divided into three groups according to their urinary albumin excretion. Group 1 had normal albumin excretion $(<30 \mathrm{mg} / 24 \mathrm{~h})$. Group 2 had microalbuminuria defined as a urinary albumin excretion of $30-300 \mathrm{mg} / 24 \mathrm{~h}$, and group 3 had clinical nephropathy ( $>300 \mathrm{mg} / 24 \mathrm{~h}$ or Albustix positive reaction in urine). The group assignment was based on measurements in three 24-h urine collections. The patients had no history of non-diabetic renal or vascular disease, and received no medication other than insulin.

Six male age-matched non-diabetic persons served as control subjects (clinical data shown in Table 1 ).

All patients and control subjects gave their informed consent, and the experimental design was approved by the Regional Ethical Committee.

\section{Experimental design}

A double tracer technique was used comparing the plasma disappearance curves in each subject after simultaneous injection of nonglycated ${ }^{13 i} \mathrm{I}$-albumin and glycated ${ }^{125} \mathrm{I}$-albumin (both tracers, Kjeller, Norway code no. IK.23 S and IT.23 S).

\section{Glycation}

Glycation of ${ }^{125} \mathrm{I}$-albumin was carried out in sterile, closed vials. 'The incubation mixture consisted of $4 \mu \mathrm{Ci}{ }^{125} \mathrm{I}$-albumin $0.03 \mathrm{mg} / \mu \mathrm{Ci}$, $550 \mathrm{mmol} / 1$ glucose and $0.9 \%$ benzylic alcohol in $25 \mathrm{mmol} / \mathrm{l}$ phosphate buffer ( $\mathrm{pH} 7.8)$ to a final volume of $2.0 \mathrm{ml}$. Prior to use the vials were incubated at $37^{\circ} \mathrm{C}$ for $48 \mathrm{~h}$. At all other times they were kept below $4^{\circ} \mathrm{C}$. No deterioration of radio chemical purity was detectable by high voltage electrophoresis during the experimental period. Control experiments with non-radioactive albumin showed this procedure to give a degree of glycation of $5.5 \mathrm{~mol}$ glucose $/ \mathrm{mol}$ albumin as measured with the furosine method [17]. ${ }^{125}$ I-albumin was assumed to be glycated to a similar level. For comparison, albumin from a group of moderately regulated diabetic patients $\left(\mathrm{HbA}_{1 \mathrm{c}}=9.5 \pm 1.0, n=17\right)$ was 
Table 1. Clinical parameters

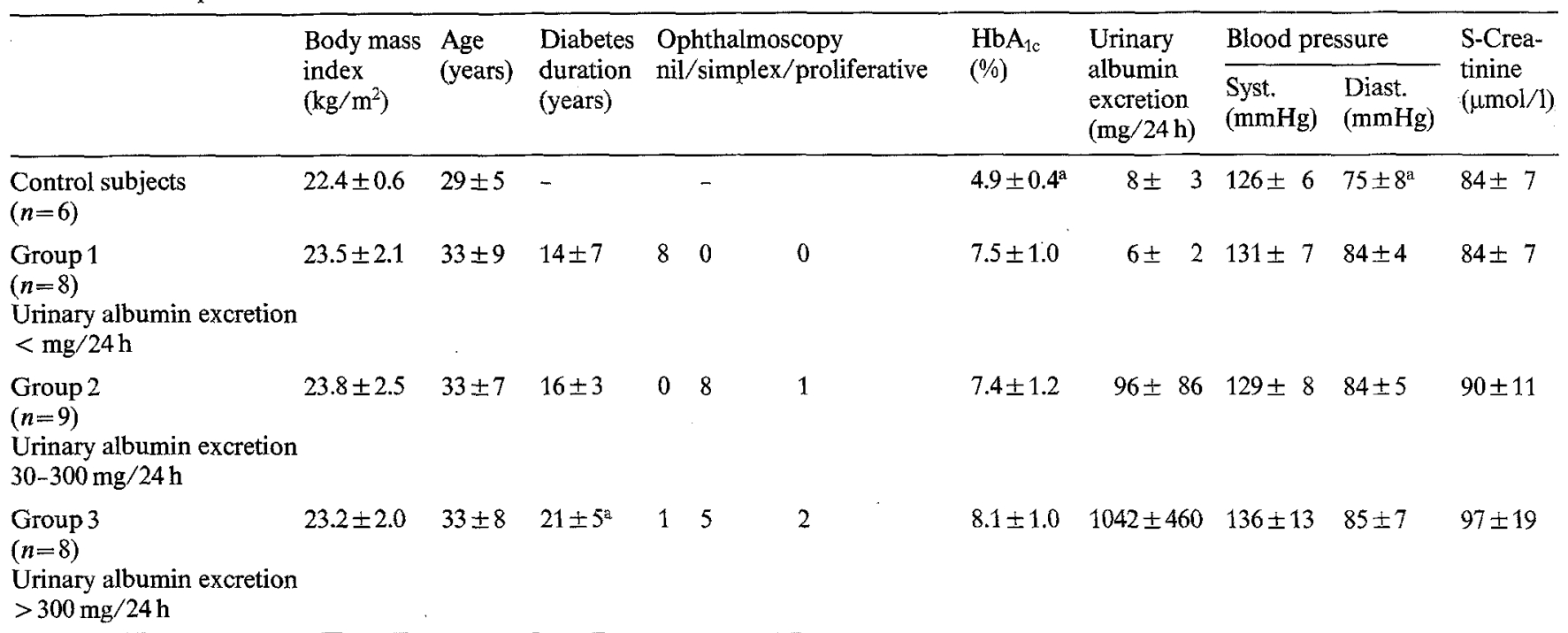

Values are given as mean $\pm \mathrm{SD}$. a denotes statistically significant difference between the group in question and the other groups ( $p<0.05$ )

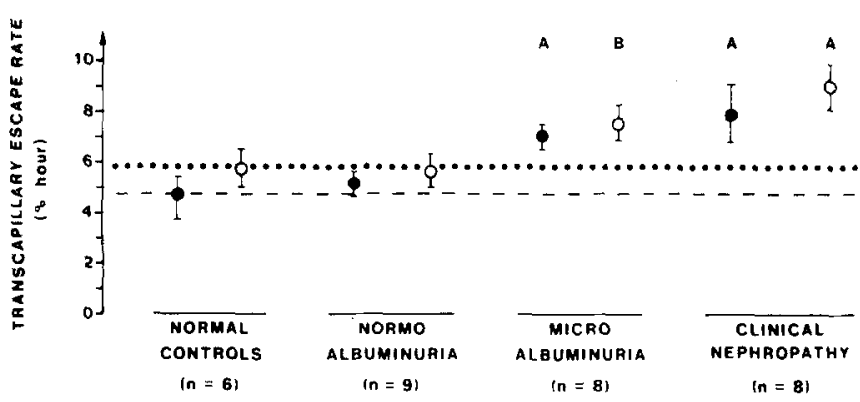

Fig. 1. Transcapillary escape rate of glycated (closed circles) and nonglycated (open circles) albumin in 25 diabetic patients and 6 normal controls. A denotes significant difference from normal controls and patients with normoalbuminuria $(p<0.05)$. B denotes significant difference from patients with normoalbuminuria $(p<0.05)$

found to be glycated to a degree of $0.83 \pm 0.1 \mathrm{~mol}$ glucose $/ \mathrm{mol} \mathrm{albu-}$ min as measured with the same method.

The molecular size of glycated ${ }^{125}$ I-tracer was estimated by diffusion in agar [18] and was not significantly different from that of untreated ${ }^{125} \mathrm{I}$-albumin or ${ }^{131} \mathrm{I}$-albumin in accordance with the small hypothetical increase in molecular weight, i.e. no polymerization or splitting of the albumin tracer had occurred.

\section{Transcapillary escape rate (TER)}

TER was measured as described by Parving [1]. The patients were studied in the supine position after a 1-h rest. Immediately prior to injection, $4 \mu \mathrm{Ci}$ of unmodified ${ }^{131} \mathrm{I}$-albumin $0.013 \mathrm{mg} / \mu \mathrm{Ci}$ was added to the incubation vial containing glycated ${ }^{125} \mathrm{I}$-albumin. For each experiment, 1-2 ml of this final mixture was injected intravenously in one arm corresponding to approximately $2 \mu \mathrm{Ci}$ of both tracers. Standards were prepared from the same vial and the precise volume for injection and standard determined by weight. After injection, $10 \mathrm{ml}$ blood samples were drawn from the contralateral arm every 10 min during the first hour. The ${ }^{125} I$ and ${ }^{131}$ I-activity of the samples were measured simultaneously in a two-channel scintillation counter. All samples were corrected for radio decay, and the activity expressed as $\mathrm{cpm} / \mathrm{mg}$ total plasma protein to compensate for changes in plasma volume during the TER measurements. The TER was calculated as the disappearance rate constant. To estimate the relative clearance, additional samples were taken 3 and 5 days later, and the ratio in plasma normalized to the calculated zero ratio determined by retropolation of the curves $($ zero ratio $=1.0)$.

\begin{abstract}
Assays
The urinary albumin excretion was measured using an ELISA assay [13]. The interassay variation was $9 \%$.

$H b A_{1 c}$ was measured by a chromatographic technique [14]. The normal range was $4.1-6.4 \%$.

$S$-creatinine was mesured by a reaction rate kinetic principle eliminating pseudo creatinines [15]. The interassay variation was $2.5 \%$.

Statistical analysis: Results are given as mean \pm SD. The paired and unpaired Student's t-tests were used for comparison within and between the groups. A $p$ value of 0.05 was considered significant.
\end{abstract}

\section{Results}

A close match with regard to age was obtained in the study (Table 1). The diabetes duration was longer in group 3. TER of non-glycated albumin was similar in group 1 and control subjects. It was significantly higher $(p<0.05)$ in groups 2 and 3 (Fig. 1).

TER of glycated albumin was slightly lower than for non-glycated albumin in all groups, but the difference reached statistical significance only in normal controls (ratio $0.80 \pm 0.19, n=6, p<0.05$ ) (Table 2). Relative metabolic clearances assessed by the normalized tracer ratio 3 and 5 days after injection showed no significant difference in metabolic handling (Table 2).

\section{Discussion}

In this study a degree of glycation of albumin tracer exceeding that seen in moderately regulated diabetic patients was obtained at least five times. In accordance with previous findings, the TER of unmodified albumin was elevated in patients with microalbuminuria and overt nephropathy [1-4]. The TER of glycated albumin was slightly lower. The decrease was not due to any difference in radiochemical purity or polymerization, suggesting a change in molecular properties associated 
Table 2. Plasma tracer ratio with time and ratio between the transcapillary escape rate of glycated and non-glycated albumin

\begin{tabular}{|c|c|c|c|c|}
\hline \multirow[t]{2}{*}{ Day of study } & \multicolumn{3}{|c|}{$\begin{array}{l}\text { Ratio of plasma albumin } \\
\text { (glycated/non-glycated) }\end{array}$} & \multirow{2}{*}{$\begin{array}{l}\text { Ratio of tran- } \\
\text { scapillary es- } \\
\text { cape rate of al- } \\
\text { bumin (glycat- } \\
\text { ed/non-glycat- } \\
\text { ed) }\end{array}$} \\
\hline & 0 & 3 days & 5 days & \\
\hline $\begin{array}{l}\text { Control subjects } \\
(n=6)\end{array}$ & 1.0 & $0.99 \pm 0.03$ & $0.95 \pm 0.05$ & $0.80 \pm 0.19^{\mathrm{a}}$ \\
\hline $\begin{array}{l}\text { Group } 1 \\
(n=8) \\
\text { Urinary albumin } \\
\text { excretion } \\
<30 \mathrm{mg} / 24 \mathrm{~h}\end{array}$ & 1.0 & $0.99 \pm 0.03$ & $0.97 \pm 0.04$ & $0.93 \pm 0.20$ \\
\hline $\begin{array}{l}\text { Group } 2 \\
(n=9) \\
\text { Urinary albumin } \\
\text { excretion } \\
30-300 \mathrm{mg} / 24 \mathrm{~h}\end{array}$ & 1.0 & $1.01 \pm 0.02$ & $1.01 \pm 0.02$ & $0.95 \pm 0.24$ \\
\hline $\begin{array}{l}\text { Group } 3 \\
(n=8) . \\
\text { Urinary albumin } \\
\text { excretion } \\
>300 \mathrm{mg} / 24 \mathrm{~h}\end{array}$ & 1.0 & $0.98 \pm 0.04$ & $0.98 \pm 0.04$ & $0.85 \pm 0.22$ \\
\hline
\end{tabular}

Values are given as mean \pm SD. ${ }^{\text {a }}$ Denotes statistical difference from $1.0(p<0.01)$

with glycation apart from the minute increase in relative size. Glycation of proteins takes place at the basic amino acid lysine, thereby slightly increasing the net anionic charge of the compound [16]. In studies of renal glomerular permeability, repulsion between fixed anionic charges of the basement membrane and the negative charge of albumin has been shown to constitute an important part of the filter hindrance [7, 8]. A similar mechanism also present in non-renal capillaries or in the interstitial space would be in accordance with these results. A lower TER of glycated albumin in comparison to TER of non-glycated albumin is contradictory to the in vitro experiments by others $[9,10]$, but supports our own findings of a reduced renal clearance of glycated albumin in diabetes [11]. The unchanged plasma ratio of the tracers 3 and 5 days after injection indicates similar metabolism of the two albumins.

We conclude that TER of glycated albumin in man is slightly lower than TER of unmodified albumin in accordance with an increase in electrical charge. We confirmed that patients with increased urinary albumin excretion have increased TER of albumin, independent of whether albumin is glycated. Our results are not consistent with any preferential endothelial uptake or transfer of glycated albumin in either control subjects or in diabetic patients. However, this does not exclude that glycation of structures on vessel surfaces contributes to the development of late diabetic complications.

Acknowledgements. This work was supported by grants from The Danish Diabetes Association. Ms. M.Deckert and Ms. H. Foght are thanked for their skilful technical assistance. Dr. P. Sejrsen of the Institute of Medical Physiology B, University of Copenhagen, is thanked for carrying out the tracer control experiments by the diffusion in agar technique.

\section{References}

1. Parving HH, Munkgaard Rasmussen S (1973) Transcapillary escape rate of albumin and plasma volume in short- and long-term juvenile diabetics. Scand J Clin Lab Invest 32: 81-87

2. Parving $\mathbf{H H}$, Rossing N (1973) Simultaneous determination of the transcapillary escape rate of albumin and IgG in the normal and long-term juvenile diabetic subjects. Scand J Clin Lab Invest 32: 239-244

3. Fauchald F, Norseth J, Jervell J (1985) Transcapillary colloid osmotic gradient, plasma volume and interstitial fluid volume in long-term Type 1 (insulin-dependent) diabetes. Diabetologia 28: 269-273

4. Feldt-Rasmussen B (1986) Increased transcapillary escape rate of albumin in insulin-dependent diabetic patients with microalbuminuria. Diabetologia 29: 282-286

5. Parving $\mathrm{HH}$, Kastrup $\mathrm{H}$, Smidt UM, Andersen AR, Feldt-Rasmussen B, Sandahl Christiansen J (1984) Impaired autoregulation and glomerular filtration rate in Type I (insulin-dependent) diabetic patients with nephropathy. Diabetologia 27:547-552

6. Hostetter TH, Kemke HG, Brenner BK (1982) The case for intrarenal hypertension in the mediation and progression of diabetic and other glomerulopaties. Am J Med 72:375-380

7. Viberti G, Keen $H$ (1984) The pattern of proteinuria in diabetes mellitus. Diabetes 33: 686-692

8. Brenner BM, Hostetter TH, Humes HD (1978) Molecular basis of proteinuria of glomerular origin. N Engl J Med 298: 826-833

9. Williams SK, Devenny JS, Bitensky MW (1981) Micropinozytic ingestion of glycosylated albumin by isolated microvessels: possible role in pathogenesis of diabetic microangiopathy. Proc Natl Acad Sci USA 78: 2393-2397

10. Lorenzi M, Bagliero E, Markney B, Henriksen T, Witztum JL and Sampietro T (1984) Interaction of human endothelial cells with elevated glucose concentrations and native and glycosylated low density proteins. Diabetologia $26: 218-222$

11. Kverneland A, Feldt-Rasmussen B, Vidal P, Welinder B, BentHansen L, Deckert T, Søegaard U (1986) Evidence of changes in renal charge selectivity in patients with insulin-dependent diabetes mellitus. Diabetologia 29: 634-39

12. Ghiggeri GM, Candiano G, Delfino G, Brandini F, Querodo C (1984) Glycosyl albumin and diabetic microalbuminuria: demonstration of an altered renal handling. Kidney Int 25: 565-570

13. Feldt-Rasmussen B, Dinesen B, Deckert M (1985) Enzyme immuno assay - an improved determination of urinary albumin in diabetics with incipient nephropathy. Scan J Clin Lab Invest 45: 539-544

14. Svendsen PAa, Christiansen JS, Søegaard U, Welinder BS, Nerup J (1980) Rapid change in chromatographically determined Haemoglobin $\mathrm{A}_{1 \mathrm{c}}$ induced by short-term changes in glucose concentrations. Diabetologia 19: 130-136

15. Larsen K (1972) Creatinine assay by a reation-kinetic principle. Clin Chim Acta 41: 209-17

16. Day JF, Thorpe SK, Baynes JW (1979) Nonenzymatically glycosylated albumin. J Biol Chem 254: 595-597

17. Schleicher E, Wieland OH (1981) Specific quantitation by HPLC of protein (lysine) bound glucose in human serum albumin and other glycosylated proteins. J Clin Chem Clin Biochem 19: 81-87

18. Paaske W (1979) Kapillærpermeabilitet. Dissertation. With an English summary. F.A. D. L., Copenhagen 100-101

Received: 6 June 1986

and in revised form: 18 November 1986

Dr. Lasse Bent-Hansen

Steno Memorial Hospital

2, Niels Steensens Vej

DK-2820 Gentofte

Denmark 